\title{
Representação do (não-)excecionalismo lusotropicalista: A viagem ao mundo colonial de Maria da Graça Freire
}

\author{
Susana Pimenta/Orquídea Ribeiro \\ Universidade de Trás-os-Montes e Alto Douro
}

\begin{abstract}
Resumo:
Neste artigo, pretende-se indagar sobre a representação do excecionalismo lusotropicalista do "modo de estar português no mundo", assente na teoria do lusotropicalismo de Gilberto Freyre, na visão da escritora portuguesa Maria da Graça Freire (1918-1993), em particular nas obras A primeira viagem, de 1953 e A terra foi-lhe negada, de 1958, onde se verifica uma oposição dúbia à "exceção" advogada pela retórica lusotropicalista das políticas do império colonial português. Por um lado, confirma-se uma oposição ao lusotropicalismo, isto é, a aptidão "inata" do homem português em se adaptar aos trópicos, em termos humanos, sociais e físicos, cultivando uma "harmoniosa" miscigenação entre as diferentes raças; por outro, verifica-se "uma mixórdia colonial-fascista", num discurso amenamente politizado e integrado na ideologia colonial do regime do Estado Novo.
\end{abstract}

Palavras-chave: Lusotropicalismo, identidade, colonialismo, Maria da Graça Freire.

\begin{abstract}
:
This article aims to inquire about the representation of the lusotropicalist exceptionalism of the "Portuguese way of being in the world", based on Gilberto Freyre's theory of lusotropicalism, according to the interpretation of the Portuguese writer Maria da Graça Freire (19181993), in particular in the works $A$ primeira viagem (1953) and A terra foi-lhe negada (1958), where there is dubious opposition to the "exception" advocated by the lusotropicalist rhetoric of the policies of the Portuguese colonial empire. On the one hand, an opposition to Lusotropicalism is confirmed, that is, the 'innate' aptitude of the Portuguese man to adapt to the tropics, in human, social and physical terms, cultivating a 'harmonious' miscegenation between the different races; on the other hand, there is 'a colonial-fascist mix', in a mildly politicised discourse integrated into the colonial ideology of the regime of the Estado Novo.
\end{abstract}

Keywords: Lusotropicalism, identity, colonialism, Maria da Graça Freire

\section{Introdução}

Por forma a combater os resquícios de colonialidade que ainda possam sobreviver nos discursos sociais e políticos da atualidade em Portugal, considera-se pertinente a revisitação das narrativas coloniais, uma vez que são fontes fundamentais para a História, para a memória e para o entendimento do passado colonial português em África, pois, tal como afirma Ansgar Nünning, "as ficções literárias da memória não só fornecem um laboratório que torna observáveis os processos complexos, dinâmicos e recíprocos da recordação e do esquecimento, como geram conhecimento sobre a relação entre memória e esquecimento" (Nünning 241). 
Depois da Revolução dos Cravos, houve um silenciamento incompreensível destas fontes, o que pode ser explicado, de acordo com António Costa Pinto, com a existência de "um 'ajuste de contas' com o passado ditatorial, mas não com a parte colonial do mesmo, sobrevivendo no discurso político e nas instituições um difuso excepcionalismo lusotropicalista" (Pinto).

Neste artigo, pretende-se indagar sobre a representação do não-excecionalismo lusotropicalista do mundo colonial português na visão da escritora Maria da Graça Freire, em particular nas obras A primeira viagem, de 1953, e A terra foi-lhe negada, de 1958, onde se sugere, por um lado, uma oposição à "exceção" lusotropicalista do império colonial português, isto é, à aptidão "inata" do homem português em se adaptar aos trópicos, em termos humanos, sociais e físicos, cultivando uma "harmoniosa" miscigenação entre as diferentes raças; por outro, verifica-se "uma mixórdia colonial-fascista" (Silva 59) num discurso amenamente politizado, justificado pela proximidade que a autora tinha ao regime de António de Oliveira Salazar.

\section{Porquê revisitar as narrativas portuguesas de índole colonial do século XX?}

Achille Mbembe considera que a representação da experiência colonial vai "desde a comemoração ativa ao esquecimento, passando pela nostalgia, pela ficção, pelo recalcamento, pela amnésia e pela reapropriação, até diversas formas de instrumentalização" (Mbembe 179-80), defendendo que na memória o importante é lutar contra a resistência do reconhecimento do passado, fazendo-se uma "crítica ao tempo e aos artefactos" (Mbembe 180).

Como afirma Eduardo Lourenço, em Portugal "antes do 25 de Abril [de 1974] não era necessário discutir os problemas africanos. Depois do 25 de Abril, tudo se passa como se não fosse necessário, ou melhor, como se já não fosse necessário" (Lourenço 203). No panorama contemporâneo, é necessário remexer o "arquivo" e recolher todos os testemunhos possíveis, independentemente do seu caráter político, ideológico, literário, jornalístico ou outro; por não ter sido remexido, criou-se um silêncio (uma desmemória) de mais de quarenta anos, como se a questão colonial portuguesa tivesse sido resolvida ou superada pelos portugueses.

Para combater resquícios colonialistas que ainda existem nos diversos discursos do nosso quotidiano português (Henriques, Racismo em português; Henriques, Racismo no país) é necessário conhecer o tipo de discurso que deu origem à aceitação massiva da máxima de Gilberto Freyre, "o mundo que o português criou”, da qual Salazar se apropriou a favor da legitimação da colonização e a forma como chegou e sobreviveu até aos nossos dias. Como afirmou Miguel Vale de Almeida, no seminário realizado em 2018, "Uma crítica das políticas de negação: pós-lusotropicalismo, luso-Lusofonia, interculturalidade", a formação cultural contemporânea da sociedade portuguesa vive em estado de negação sobre o racismo e sobre a experiência colonial; existe um pós-lusotropicalismo, que não é mais do que a não-superação ou estado de negação da existência de um pensamento "lusotropicalista", o que o faz perpetuar. 


\section{Lusotropicalismo e narrativas de ficção}

O lusotropicalismo é a 'teoria' que permite, no contexto colonial de meados do século XX, construir a ideia de singularidade do império colonial português e legitimar a ação colonizadora em terras africanas (Castelo). Esta teoria propagou-se de diversas formas, numa "credibilidade excessiva" (Castelo 15), em particular através de diversificadas narrativas, proferidas pelas vozes mais conceituadas da ciência, da cultura, da literatura e da política portuguesas da época.

Os fundamentos desta teoria surgem a partir das obras do sociólogo brasileiro, Gilberto Freyre, que "defende que a sociedade brasileira lucrou com a intensa miscigenação que se operou no período colonial” (Castelo 137), exaltando a vocação do português para o contacto com os povos dos trópicos.

De uma forma sumária, a teoria lusotropicalista advoga a aptidão "inata" do povo português na aceitação do outro. A teoria, apoiada nos factos históricos de Portugal e das suas gentes, expõe e argumenta a singular predisposição do português para a colonização híbrida nos trópicos (Castelo), assente na mobilidade, na plasticidade e na adaptabilidade que, segundo Freyre, caracterizam o povo português. A doutrina lusotropicalista vem cimentar o "modo português de estar no mundo" que "pressupõe que o povo português tem uma maneira particular, específica, de se relacionar com os outros povos, culturas e espaços físicos, maneira que os distingue e individualiza no conjunto da humanidade" (Castelo 13).

A literatura de cariz colonial, enquanto instrumento ideológico do Estado Novo, sai reforçada com a adoção da teoria ("científica") do lusotropicalismo defendida por Gilberto Freyre e usada pelo chefe de Estado, António de Oliveira Salazar; é assim que, nos anos 40, a mística imperial atinge o seu auge com a aceitação e a politização das premissas lusotropicalistas. A tentativa de politização da literatura colonial e a adoção da visão lusotropical dão corpo à imagem que se "sonha" do império colonial português. Na verdade, ainda que tornada "científica" pela sociologia de Freyre, tratase de uma realidade "ficcionalizada" que se defende e pela qual se luta até à véspera das independências.

Como já foi referido, o lusotropicalismo vem legitimar a ação colonizadora dos portugueses e dar um cunho humanista ao pensamento colonial numa época em que as vozes da resistência já se fazem ouvir nas colónias e na metrópole. Apesar de haver uma "receção favorável" da teoria de Freyre, as interpretações divergem entre os intelectuais portugueses; uns encaram-na como a razão para o louvor da especificidade ou excecionalidade da colonização portuguesa; outros confrontam-na criticamente com a ação efetiva e com as atitudes políticas exercidas em território africano (Castelo 137). Maria da Graça Freire, escritora de relevo nos anos 50, oscila entre as várias interpretações ao longo das três obras de temática africana que publica (Azambuja; Freire, $A$ terra; Freire, Os portugueses), intentando uma autorreflexão, ainda que politizada, sobre a identidade portuguesa nos trópicos. 


\section{Maria da Graça Freire: notas biográficas}

Maria da Graça Freire (1918-1993) nasce em Benavente, irmã de Natércia Freire, destaca-se na narrativa de ficção e é considerada uma das mais salientes ficcionistas da cultura portuguesa do século XX, "de início conhecida como autora de literatura colonial" (Saraiva e Lopes 1134). Entre as várias obras de sua autoria, encontram-se três obras alusivas à questão colonial portuguesa: dois romances (A primeira viagem, $1952 \mathrm{e}$ A terra foi-lhe negada, 1958) e um ensaio intitulado Portugueses e a negritude (1971); ganha prémios literários, e um deles, o prémio Eça de Queirós, é atribuído pelo Secretariado Nacional Informação (SNI) (antes Secretariado de Propaganda Nacional-SPN), destinado a premiar a "literatura oficial" e escritores que se integrem no regime, isto é, de acordo com "a consciência corporativista da conciliação de classes, com o nacionalismo, com o imperialismo colonial, com a divisa 'Deus, Pátria, Família”' (Torgal 408).

Começa a escrever depois de casada e adota o nome do marido Azambuja, para não ser confundida com a irmã, a poetisa Natércia Freire, tal como refere em entrevista, na rubrica "Diga-nos a verdade" do Diário de Lisboa, no ano de 1953, "se adoptasse o nome de solteira, parecer-me-ia que procurava acolher-me à sua sombra" (Diário de Lisboa 1953). No entanto, quando se divorcia, passa a usar o nome de solteira, Freire.

A ida para Angola em 1937 inspira-a para a reflexão sobre a condição existencial da mulher num mundo colonial e metropolitano atravessado por preconceitos raciais e sociais. Desta estadia, surge A primeira viagem (1952), um romance de experiências pessoais que, segundo a autora, "constitui uma pequena desforra das muitas injustiças que presenciei nessa minha experiência em África” (Diário de Lisboa 1953).

\section{A viagem ao mundo colonial}

Em A primeira viagem (1952), obra galardoada com o prémio Ricardo Malheiros em 1952, Maria da Graça Azambuja narra a história de uma mulher capaz de "ir para o inferno" (Azambuja 17) atrás do marido para um casamento religioso, numa viagem de autoconhecimento, de Portugal para Angola. A obra começa por retratar a chegada de Mónica ao continente africano depois de dezasseis dias a bordo de um navio e o longo percurso de comboio que a leva até Lépi, no planalto central, para junto de André Vilar, funcionário do Caminho de Ferro de Benguela, com quem casara civilmente por procuração há quatro meses, mas que não vê há dois anos. Nesta última escala, com contornos autobiográficos, Azambuja representa a luta, a tristeza, a ânsia e a curiosidade que assolam todos aqueles que se aventuram rumo ao desconhecido:

Voltava a dissipar-se a minha [Mónica] euforia do despertar, em que me supunha senhora de uma vontade capaz de defrontar todos os obstáculos, e de vencê-los. Dominada pelo estranho poder do continente negro, capaz de sugar a alma, senti, num momento, a eternidade de me arrastar por aquelas paragens, frouxa e infeliz, como o mais infeliz dos condenados - aquele que desprezasse a própria liberdade. (Azambuja 154-55)

A primeira viagem, numa época em que a subalternidade da mulher é visível, é percursora da emancipação da mulher no mundo das letras e das artes em Portugal, sendo 
um romance da condição feminina, onde não há "rebelião nem desistência: antes, a protagonista redefine os seus limites como mulher e os vence, em nome de uma redescoberta interior despoletada pela terra [africana], pelo sofrimento e pela regeneração de si" (Lino 129), inovando ainda na centralidade de sujeitos subalternos femininos no universo colonial ao longo da narrativa.

Mónica atravessa Angola de comboio até ao seu destino. Outras mulheres viajam sozinhas ou com crianças no mesmo comboio - "mulheres de meia idade com aspecto de provincianas modestas, vestidas para um passeio à cidade" (Azambuja 6) - com imensos sacos e cestos no porta-bagagem. A impaciência infantil permite relembrar a mãe viajante a razão daquela longa viagem: "Então não te lembras do que disseram ao pai quando ele foi a Lisboa? É um sítio muito lindo, com árvores e água por todos os lados. Vamos ter uma boa casa e em pouco tempo arranjamos uma fazenda. O pai ganha muito dinheiro e depois voltamos para ao pé do avô, hein?” (Azambuja 8), remetendo para a ideia do Eldorado africano, ou o sonho da colonização, veiculada pelas políticas de povoamento branco do Estado Novo. Numa outra cabina, homens dormitam com os seus "fatos escuros de fazenda, os seus melhores fatos de pequenos lavradores" (Azambuja 7). Todos eles seguiam para Lépi, "região fertilíssima, de clima moderado, com paisagens de beleza espectaculosa, para cartazes de propaganda. Seduzidos por promessas de colonização fácil e proveitosa, ignoravam a luta que iam empreender" (Azambuja 7).

De 1900 a 1950, intenta-se uma colonização agrícola sem sucesso. Os poucos interessados que respondiam ao apelo dos governantes eram camponeses ou indivíduos pobres sem formação profissional, portanto pouco levavam para garantir o sucesso de projetos agrícolas. Além do mais, a maioria, não vingando na agricultura, enveredou pela área do comércio. A falta de correspondência entre colonos e sistema governativo, leva Henrique Galvão, em 1932, a denunciar a "mentira colossal" existente na vida administrativa da colónia Angola: "temos uma legislação perfeitíssima, copiosa, síntese das melhores doutrinas e das mais santas intenções, mas não temos, em correspondência com tanta flor de retórica arrumada em artigos e parágrafos, uma obra de colonização europeia realizada" (Galvão apud Pimenta 67). A partir dos anos 50, acreditando que alguns erros do passado pudessem ser corrigidos, há novos investimentos no povoamento branco, um projeto já desacreditado pelos sucessivos fracassos. Surge a ideia de criar grandes colonatos agrícolas, onde se fornece campos comunitários de pastagem; cada família colona recebe casa e mobiliário, sementes, animais, alfaias agrícolas e um subsídio mensal entre 1500 e 4500 escudos, esperando-se a instalação de milhares de famílias de colonos, mas sem grandes sucessos (Pimenta 66-68), tal como acontecera, a título de exemplo, a Corino; "O Estado concedeu [-lhe] um terreno que ele se propôs cultivar por suas próprias mãos, com a ajuda da mulher. Supôs que, dando-lhe o melhor sangue, a chitaca o enriqueceria. Semeava arroz e milho, criava gado, fabricava manteiga e queijo" (Azambuja 28), mas o projeto fracassa.

Maria da Graça Azambuja intenta, ao longo desta primeira viagem da jovem Mónica, uma crítica ao tempo e à sociedade colonial branca do ponto de vista dos colonos pobres seduzidos pela ideia imperial do homem português, conquistador e triunfante, em terras africanas. Apesar das vicissitudes do mundo colonial, Maria da Graça Azambuja, na voz de Mónica, afirma que "Não importava o nosso fracasso. Importava, apenas, que sobre as lágrimas e os êxitos de quantos iriam, como nós, toda a grandeza de uma raça lançasse no tempo as suas raízes” (Azambuja 306). 
Não há, ao longo da obra A primeira viagem, muitas referências à outra "raça" e, quando as há, os qualificadores são negativos, pelo que a aptidão inata dos portugueses na relação com os outros povos, como advoga a teoria lusotropicalista, não é evidente, tal como se pode constatar no primeiro encontro de Mónica com a mulher negra:

O contacto com uma raça diferente não me deixava imperturbável. Nos olhares que me fixavam não se me afigurava ler acolhedoras boas-vindas. Nos de uma preta, esguia e flexível, lencinho branco na cabeça e, sobre o quimono amarelo que lhe dissimulava o peito pontiagudo, uma porção de colares, surpreendi um lampejo de irónica animosidade. (Azambuja 19)

Mónica refere ainda que "estar entre brancos é considerarmo-nos, indiscutivelmente, entre gente nossa, e todos os brancos se consideram altos personagens em relação aos nativos" (Azambuja 69).

O retrato da sociedade negra no mundo colonial é comum às descrições realizadas por outros escritores coevos de temáticas africanas, tais como Guilhermina de Azeredo ou Reis Ventura (Pimenta). Por um lado, as características comportamentais atribuídas ao "outro" incidem sobretudo na embriaguez, no vício, na preguiça:

parecera meio embriagado, e, agora, nem se atrevia a lavar pratos. A cangonha, estava bem de ver, a maldita cangonha, o estupefaciente do negro. Não calei a minha indignação. - Preto quando fuma é igual aos bichos. Não tem vergonha de dar cabo da saúde com essa porcaria? (Azambuja 175).

Por outro, predominam sentimentos de compaixão - "Saparalo fora sempre um preto dedicado e cumpridor" (Azambuja 175) - e de infantilização do negro, legitimando desta forma a "missão civilizadora" do colono português: "A par desse e doutros defeitos, [o negro Saparalo] mostrava-se dócil e possuía uma ingenuidade que igualava aos cinco anos de Bianca. Fazia-me perguntas infantis e escutava religiosamente as histórias que eu contava à pequenita" (Azambuja 131). Quanto à mulher negra, é realçado o exotismo erotizado: "possuir uma mulher em plena selva, ao som de um batuque à lua, é feitiço que não esquece. A negra é lúbrica..." (Azambuja 72). Na opinião de Corino, um colono há largos anos em Angola, "é impossível, por maior vigilância que haja, modificar-lhes os costumes" (Azambuja 24).

À chegada da aventurosa viagem, Mónica tem a ajuda dos amigos Ângela e José Alberto que a acolhem numa "velha habitação de madeira e zinco, os bidões que serviam de bancos aos meus hospedeiros" (Azambuja 10). Ângela representa o descontentamento e a desilusão da experiência colonial; é "uma mulherzinha pouco mais ou menos da minha idade e mostrava-se destrambelhada, quezilenta como uma velha. Nunca em sua boca floria a graça de um sorriso" (Azambuja 10). O marido, o maquinista José Aberto abandona os estudos universitários na metrópole, em Lisboa, "seduzido pela promessa de um largo futuro" depara-se com uma situação desastrosa, pois "os ganhos reduzidos só à custa de privações inconcebíveis permitiam amealhar uns angolares; as instalações péssimas, deprimente o regime em que se vivia. O fito do casal resumia-se em economizar ferozmente, a fim de voltar à metrópole" (Azambuja 1011).

Os símbolos cénicos das personagens que formam o casal, que mais parecem "um casal de jovens revolucionários exilados" (Azambuja 11), esfarrapam a crença idílica 
que Mónica traz sem, no entanto, a destruir, pois quanto maior dificuldade sentia, maior é a exaltação: "Quase me sentia gloriosa. Tivera uma coragem excepcional em vir, sozinha, reunir-me a André. Começava a viver a minha vida e todas as emoções me pareciam grandiosas" (Azambuja 14), sentindo que:

A minha missão era diferente da que supusera, mas a excelência do sonho reside em não nos fazer tropeçar nas realidades. André precisava, não apenas de carícias, mas de cuidados, de dádiva discreta de todos os instantes para lhe tornar a vida mais fácil e cómoda. (Azambuja 54)

No entanto, o reencontro com o marido, André Vilar, funcionário dos Caminhos de Ferro, num cenário tanto estranho quanto familiar, julgando-se "em qualquer aldeia da Metrópole" (Azambuja 37-38), é na verdade um mar de deceções; depara-se com um homem, assimilado pelos vícios "naturais" do homem negro: a preguiça, o jogo, as mulheres. Ao contrário do que era esperado, André não amealhara dinheiro e está instalado numa casa pouco asseada e pobre, o que indigna a sua mulher. Descobre ainda que mantém um caso extraconjugal com a filha de D. Eugénia e do seu chefe hierárquico, Mariana, de 17 anos, por quem estava apaixonado, mas, à chegada da mulher, André renuncia à jovem "para transigir com o convencionalismo que a civilização lhe impunha ainda" (Azambuja 59), atraiçoando-se a si mesmo. Quanto à atitude irreverente de Mariana, explica-se pelo local onde é educada, pois "Uma rapariga de boa família não pode obter aqui [no mato de Angola] uma educação razoável" (Azambuja 64). A infidelidade, o jogo e a falta de riqueza são "justificados" pela solidão do homem colono, habitando o mato, onde "as distrações de um homem só, consistiam em beber e jogar. Ora isso nunca fizera prosperar ninguém” (Azambuja 55).

Após oito anos de estadia em Angola, o casal acaba por regressar com espírito de esperança e vontade de recomeçar em Lisboa, onde há maiores possibilidades, à imagem da situação de Giorgio e mulher em terras africanas, "esses sim, são verdadeiros tipos de colonos. Suportam tudo com uma resignação que você nunca terá, sempre prontos a recomeçar" (Azambuja 201), em qualquer parte do mundo.

Em 1958, Maria da Graça Azambuja, doravante Maria da Graça Freire, apresenta A terra foi-lhe negada, obra galardoada, como já foi referido, com o prémio Eça de Queirós. Apesar da ação se desenrolar na metrópole, a narrativa é uma "viagem" ao universo colonial, na voz de Inês, narradora autobiográfica fictícia, onde a problemática da miscigenação é analisada à luz dos tempos em que a história decorre, isto é, meados do século XX. Para o efeito, Inês percorre "meticulosamente os caminhos da memória, se bem que é muito difícil uma introspeção honesta, sujeitos como estamos a inúmeros preconceitos deformadores" (Freire, $A$ terra 44 ), comprometendo-se a "respeitar a verdade, embora nela transpareçam os meus erros e defeitos, ser-lhe-ei fiel" (Freire, $A$ terra 52).

A terra foi-lhe negada conta a história de Inês e Floriano, jovem músico, natural de Angola e mulato. À época, raros são os romances onde a miscigenação se dá entre mulher branca e homem negro. Maria da Graça Freire, na irreverência de uma mulher escritora emancipada, quebra os convencionalismos sociais e apresenta uma estrutura familiar invulgar, para traçar um retrato de mestiçagem, que não tem à partida futuro por força de condicionalismos biológicos e de educação, tratando-se, segundo Artur Portela, de uma análise de "comportamento de raças", verificando-se entre o casal um 
"antagonismo de condição, avatares que o plasma carreia e um determinismo que, embora não seja inverso se contraria, ou pelo menos não se adapta integralmente à existência em comum" (Portela).

Álvaro Salema, na nota paratextual à obra $A$ terra foi-lhe negada, afirma que Maria da Graça Freire "faz-nos sentir, escutar, perscrutar, a alma de duas figuras: um negro e uma branca, unidos por um matrimónio pobre, em que se deu, na verdade, uma total fusão e infusão carnais, que não são, todavia, suficientes para os unir espiritualmente" (Freire, $A$ terra). Por outro lado, "Floriano, o negro, não conseguiu ainda dominar por completo os seus instintos de versatilidade, infantilidade, fruste arrogância, prazer fácil, e outros. Permanecem nele latentes, potencialmente, complexos e inibições, que se destacam com incidência num meio que não é originário. Mas Inês ama-o, profundamente, como mulher e como amante, num carinhoso sentimento quase maternal" (Freire, A terra).

As primeiras impressões relativas a Floriano, um "mestiço" descrito como "francamente escuro, quase preto", prenderam a atenção "surpreendida e desdenhosa" (Freire, $A$ terra 38 ) de Inês; despertaram de igual modo todas as imagens que lhe foram construídas e incutidas pela educação ou formação em relação à raça negra: "Meu pai falava dele com desprezo: - Negro cheira sempre a sanzala" (Freire, $A$ terra 40 ).

Eu nunca tratara com mulatos, no meu entender muito mais perto da raça negra do que da branca. Tinha ideias feitas a esse respeito, originadas por alguns conceitos, alusões e insinuações que nos são fornecidos desde crianças e prosseguem através dos livros e das fitas. (Freire, $A$ terra 39-40)

Numa época em que, segundo a voz de Romero, "Todos gritam e ninguém se entende" (Freire, A terra 47), os preconceitos e os problemas raciais tomam lugar nas discussões mais vulgares. Eunice, mulata, orgulha-se de não conhecer bem África, como se, segundo Inês, "o facto de ter vindo criança para a Metrópole aclarasse a sua pele e lhe conferisse um lugar de raiz na comunidade" (Freire, $A$ terra 46). Numa atitude altiva e para rematar o confronto, relata: "Aquela mulata julgava talvez impor-se-me. Eu abater-lhe-ia a arrogância. - O ambiente de infância conta muito mais do que as pessoas supõem. A nossa personalidade constrói-se sobre ele" (Freire, A terra 46).

No final, apesar do amor de Inês, a condição (congénita) de Floriano não permite que a união tenha futuro. Curiosamente, Floriano morre de doença no fígado, em sintonia com a representação estereotipada do discurso colonialista racista, que atribui vícios de álcool e drogas que alteram a razão a homens africanos, mesmo aqueles que parecem comportar-se de acordo com as normas da "civilização".

\section{Considerações finais}

A retórica do (excecionalismo) lusotropical em Maria da Graça Freire é oscilante e gradual; cresce à medida que a "teoria" de Gilberto Freyre se instala nos discursos oficiais; ou talvez à medida que o sentimento de "perda eminente" das colónias se intensifica e oscila entre a crítica às políticas da colonização e exaltação da "missão civilizadora" junto do homem negro. Recorde-se que Maria da Graça Freire sempre foi próxima do regime salazarista. Tal como Diogo Ramada Curto afirma, "num regime 
onde a censura institucional e interna se encontrava bem enraizada, os que falavam a partir de dentre pareciam ter o direito de transgredir, a ponto de porem em causa os fundamentos da ideologia lusotropicalista, a par do machismo, e de poderem falar naturalmente do modo como a PIDE [Polícia Internacional e Defesa do Estado - 194569] perseguia os comunistas" (Curto 119), sendo que "os que mais colaboravam com o regime eram os que mais ceticismo e descrença podiam mostrar em relação aos fundamentos ideológicos do mesmo" (Curto 119). Aliás, Curto refere ainda, e em relação a $A$ terra foi-lhe negada, que se certas páginas "tivessem sido escritas por um oposicionista ao regime, teriam levado à censura do livro e à perseguição do seu autor" (Curto 119), tal como acontecera a Castro Soromenho e à obra Terra Morta, censurada em 1945, por denunciar a relação entre brancos e negros no contexto da colonização portuguesa, levantando questões incómodas para a imagem do império colonial que o regime pretendia criar (Pimenta).

Em A primeira viagem, há a crítica às políticas de colonização dos anos 40 que incentivavam trabalhadores a estabelecerem-se em África, em particular no interior de Angola, sem as menores condições de habitabilidade e sustento, pois o sustento através da agricultura é inviável, por força da imprevisibilidade das pragas. Em termos sociais e culturais, não há contacto harmonioso multirracial, havendo choques culturais constantes, e a miscigenação dá-se, principalmente, pela prostituição da mulher negra.

Segundo a mesma obra, o ambiente exótico e selvagem influi no comportamento dos portugueses de forma negativa, contrariando a capacidade de adaptabilidade aos trópicos, como são exemplo, a leviandade de Mariana, jovem nascida e criada em Angola; Ângela, que abandona a ideia de ser mãe, pois África não é local para criar os filhos; André, funcionário do estado, assimilando-se, quer dedicar-se à caça, tal como os negros e deixa-se levar pelos vícios; ou o fracasso e a perda de esperança de António, que o leva ao suicídio.

$\mathrm{Na}$ obra em apreço, o homem português não supera o clima, não se adapta ao meio, não mantém boas relações com o homem ou a mulher negra, existindo nos vários quadrantes da sociedade colonial sinais de violência e racismo. Neste sentido, esta obra publicada em 1952, não espelha a retórica lusotropicalista, antes critica a figura e a situação do português comum "emigrante" em terras africanas. A obra, um relato de experiências pessoais da autora, representa a sociedade colonial branca e as condições miseráveis em que vive. Este retrato social convida sobretudo as mulheres a não empreenderem a viagem até Angola, propagandeada como uma terra fértil e de fortuna fácil.

Em Portugal, a instituição oficial do lusotropicalismo dá-se, precisamente, a partir da viagem às colónias de Gilberto Freyre realizada em 1951 (Castelo). Não será de admirar que o discurso lusotropical de Maria da Graça Freire surja nas obras seguintes com maior força. Depreende-se, assim, que o discurso lusotropical em Freire surge após a publicação de $A$ terra foi-lhe negada em 1958 e consolidada sobretudo nos ensaios que começa a publicar no Diário de Lisboa, mais tarde publicados pela Agência-Geral do Ultramar, Os portugueses e a negritude em 1971.

Maria da Graça Freire, em 1971, quase em véspera da Revolução de Abril de 1974, publica o ensaio Os Portugueses e a negritude, onde se posiciona em relação à ideologia colonial, afirmando que "ao contrário da maioria dos povos, nunca o português visou instalar-se como usurpador ou conquistador [...] E permanece o espírito da 
fraternidade" (Freire, Os portugueses 27). Para firmar a sua convicção, serve-se das palavras do poeta angolano Geraldo Bessa-Victor, que advoga:

Portugal não praticou uma política de discriminação ou de mera assimilação, mas uma profunda política de integração dos povos africanos na nacionalidade. Mas ao operar-se a integração dá-se uma verdadeira simbiose de valores lusitanos com valores africanos que se integram na alma lusíada passando a ser autenticamente africanos; é também o branco português que através da vida do mato adere aos sentimentos e pensamentos do homem negro de África e às realidades espirituais da terra, estudando uma e outra, compreendendo-a e amando-a. (Bessa-Victor apud Freire, Os portugueses 30) [o que contraria a ideia explanada na obra $A$ primeira viagem $]$

A autora acrescenta ainda que ao "revigorar o conceito de meta-raça de Gilberto Freyre, vemos o negro português, ou o mestiço, de vastas possibilidades intelectuais e capacidade de conhecimento, diferente de qualquer outro homem da sua cor" (Freire, Os portugueses 31); tal máxima não se observa em $A$ terra foi-lhe negada, pois Floriano, o mestiço, não consegue "superar-se" ou "civilizar-se" no seu todo, por culpa da sua condição biológica. Neste sentido, ainda no ensaio Portugueses e a negritude, denota-se uma reformulação de discurso no que respeita à ideia da influência do espaço (físico, social e colonial) nas atitudes comportamentais e da integração no espírito nacional dos negros, sendo a assimilação recíproca, positiva e harmoniosa:

A integração no espírito nacional dá-lhes o ar de unidade que se observa numa família mesmo quando os seus membros são aparentemente distintos uns dos outros. A rapariga ou a mulher de Angola tem maneira recatada e sonhadora, o sinal de saudosismo, uma das características do universalismo português, tal como as suas irmãs da metrópole assim como muitos brancos radicados em África têm em si a marca do ambiente. (Freire, Os portugueses 31) [cf. Assimilação negativa no exemplo da "leviana" Mariana (A primeira viagem), educada em Angola; ou ainda, o exemplo da mestiça Eunice ( $A$ terra foi-lhe negada), educada na metrópole, que renuncia a sua "negritude".]

Como já foi referido, e para finalizar, a retórica lusotropical em Maria da Graça Freire é progressiva e consentânea com a ideologia do império colonial português, à medida que a cientificidade ou "teoria" do lusotropicalismo ocupa espaço nos discursos oficiais do regime; ou, numa outra perspetiva, fortalece-se à medida que o sentimento de perda eminente das colónias africanas se intensifica.

\section{Referências bibliográficas}

Almeida, Miguel Vale. "Uma crítica das políticas de negação: pós-lusotropicalismo, luso-Lusofonia, interculturalidade". 2018. Web. 30 dezembro 2020.

Azambuja, Maria da Graça. A primeira viagem. Lisboa: Parceria António Maria Pereira, 1952.

Castelo, Cláudia. "O modo português de estar no mundo": o luso-tropicalismo e a ideologia portuguesa (1933-1961). Porto: Edições Afrontamento, 2011. 
Curto, Diogo Ramada. "Dos brancos pobres ao racismo". Revista E, Semanário 2384, 7 julho 2018. Web. 30 dezembro 2020.

Diário de Lisboa. "Diga-nos a verdade: Maria da Graça Freire" (Entrevista). 23 de janeiro de 1953. Web. 30 dezembro 2020.

Freire, Maria da Graça. A terra foi-lhe negada. Lisboa: Portugália Editora, 1958.

Freire, Maria da Graça. Os portugueses e a negritude. Lisboa: Agência Geral da Colónias, 1971.

Henriques, Joana Gorjão. Racismo em português. O lado esquecido do colonialismo. Lisboa: Edições Tinta-da-china, 2016.

Henriques, Joana Gorjão. Racismo no país dos brancos costumes. Lisboa: Edições Tinta-dachina, 2018.

Lino, Pedro Sena. "Só a viagem responde, anotações para uma leitura de Maria da Graça Freire". Revista Terras d'Água 2 (2002): 129-135.

Lourenço, Eduardo. Do colonialismo como nosso impensado. Lisboa: Gradiva, 2014.

Mbembe, Achille. Crítica da rąão negra. Lisboa: Antígona, 2014.

Nünning, Ansgar. "A 'verdade da memória' e o 'frágil poder da memória': a literatura como meio de explorar ficções e enquadramento da memória”. Estudos de Memória. Teoria e análise cultural. Ed. Fernanda Mota Alves, Luísa Afonso Soares e Cristiana Vasconcelos Rodrigues. V. N. Famalicão: Edições Húmus, 2016. 219-241.

Pimenta, Susana. Dinâmicas coloniais e pós-coloniais. Os casos de Reis Ventura, Guilhermina de Az̧eredo e Castro Soromenho. V.N. de Famaliacão: Edições Húmus, 2018.

Pinto, António Costa. "O fim do império colonial portugués". Público. Web. 30 dezembro 2020 .

Portela, Artur. "A Terra foi-lhe negada, de Maria da Graça Freire”. Diário de Lisboa, 19 fevereiro 1959. 18-19. Web. 30 dezembro 2020.

Saraiva, António José; Óscar Lopes. História da literatura portuguesa. Lisboa: Porto Editora, 1987.

Silva, Manoel Souza. Do alheio ao próprio: a poesia em Moçambique. São Paulo: Editora UFG, 1996.

Torgal, Luís Reis. "'Literatura oficial' no Estado Novo: os prémios literários do SPN/SIN”. Revista de Historia das Ideias 20 (1999): 401-420. Web. 30 dezembro 2020 . 